\title{
Saneamento descentralizado em assentamentos urbanos precários: alternativa para a universalização. Estudo de caso do Parque das Laranjeiras em Mogi Mirim, SP1
}

\section{Decentralized wastewater management in precarious settlements: Paths to universalize sewage services. Case study of Parque das Laranjeiras in Mogi Mirim,SP}

\author{
Teixeira, Clareana'; Furigo, Renata²; Samora, Patrícia³ \\ 1 Mestranda, Pontifícia Universidade Católica de Campinas - PUC Campinas, \\ Brasil, clareanamr@gmail.com \\ 2 Doutoranda Pontifícia Universidade Católica de Campinas - PUC Campinas, \\ renatafurigo@gmail.com \\ 3 Doutora, Pontifícia Universidade Católica de Campinas - PUC Campinas, \\ patricia.samora@puc-campinas.edu.br
}

\section{RESUMO}

Entre os serviços públicos considerados essenciais, o saneamento básico é o que apresenta maior defasagem em termos de cobertura no Brasil. O objetivo deste artigo é discutir as possibilidades e os limites para implantação do sistema descentralizado de saneamento em assentamentos urbanos precários, tendo por objeto empírico o Loteamento Parque das Laranjeiras em Mogi Mirim, SP. Trata-se de um estudo de caso, parte integrante da pesquisa de mestrado em Arquitetura e Urbanismo da PUC CAMPINAS, ainda em andamento, financiada pela Capes no âmbito do grupo de pesquisa "Políticas Territoriais e a Água no Meio Urbano". O método consiste em: caracterização do assentamento e da solução aventada, pelo órgão responsável, para o saneamento da área; revisão teórica sistematizando as possibilidades e métodos de saneamento descentralizado para áreas urbanas; comparação entre as possibilidades verificadas e a proposta em estudo na cidade. Espera-se, com isso, contribuir com a discussão sobre as possibilidades e limites de soluções de saneamento que envolvam o tratamento local dos efluentes, ainda que em áreas urbanas densas e complexas como são os assentamentos informais.

Palavras-chave: Habitação de interesse social; Universalização do saneamento; Gestão das águas urbanas.

\footnotetext{
ABSTRACT

The basic sanitation in Brazilian cities is the infrastructure that presents the poorest indicators. The paper aims to discuss the possibilities and the limits in regard to the adoption of decentralized wastewater treatment solutions in substandard poor urban settlements,

1 TEIXEIRA, Clareana; FURIGO, Renata; SAMORA, Patrícia. Saneamento descentralizado em assentamentos urbanos precários: alternativa para a universalização. Estudo de caso do Parque das Laranjeiras em Mogi Mirim, SP. In: II SIMPÓSIO NACIONAL DE GESTÃO E ENGENHARIA URBANA: SINGEURB, 2019, São Paulo. Anais... Porto Alegre: ANTAC, 2019.
} 
presenting the case of Parque das Laranjeiras neighborhood in the city of Mogi Mirim, SP. The study is part of a research being conducted to achieve a master degree in Architecture and Urbanism in PUC CAMPINAS. The overall method was the characterization of the settlement and the proposed solution by the local sanitation company; a review about decentralize possibilities selected to the Parque das Laranjeiras. As a result, we aim to contribute to the discussion about the viability of using decentralized solutions to the wastewater treatment in substandard urban settlements.

Keywords: Precarious settlements; Universalization of basic sanitation; Water management.

\section{INTRODUÇÃO}

A ocupação urbana e o adensamento populacional desordenado têm como uma de suas consequências a falta de infraestrutura, como saneamento básico, ocasionando diversos problemas sociais, ambientais e de saúde.

Segundo o Plano Nacional de Saneamento Básico (Brasil, 2013), apenas 50,3\% dos brasileiros têm acesso à coleta de esgoto, o que significa que mais de 100 milhões de pessoas utilizam medidas alternativas para lidar com os dejetos.

A falta de tratamento de esgoto sanitário, gera uma sobrecarga nos recursos hídricos, o que significa que em média 5,5 mil toneladas de carga orgânica por dia chegam aos cursos d'água, valor muitas vezes bem superior à sua capacidade de diluição das cargas poluidoras.

Embora o tratamento convencional de esgoto sanitário seja suficiente para 2.969 municípios, a maior parte da população brasileira está em 840 centros urbanos que demandam solução complementar ou solução conjunta para resolver o problema segundo o Atlas de Esgoto (ANA, 2017). Portanto, a necessidade de se pensar em alternativas de saneamento para além das tradicionais redes de coleta e tratamento centralizado é urgente: é certo que, para atingir a universalização, será necessário adotar medidas descentralizadas em muitos casos, sobretudo em muitos assentamentos precários urbanos.

De modo geral, sistemas descentralizados são aqueles que coletam, tratam e fazem a disposição final ou reuso do esgoto em local próximo à sua geração, diferentemente do que ocorre nos sistemas centralizados tradicionais (LIBRALATO; GHIRARDINI; AVEZZÙ, 2011).

Este trabalho apresenta o caso do bairro Parque das Laranjeiras em Mogi Mirim, SP, discutindo as oportunidades e entraves para adoção do sistema descentralizado de saneamento em um assentamento urbano precário. O local tem parte de rede instalada e encontra-se em processo de regularização fundiária. Para tanto, o Serviço de Água e Esgoto de Mogi Mirim (SAAE) pretende implantar o restante da rede e bombear os efluentes para outra bacia, único local onde há Estação de Tratamento de Esgotos (ETE). Contudo, esta já se encontra no limite de sua capacidade, ou seja, os efluentes serão lançados diretamente no ponto da bacia em que a concessionária tem permissão para lançar. Por outro lado, a concessionária descarta a possibilidade de adoção de ETE Compacta, que permitiria tratar in loco os efluentes, mas tem impacto na vazão na bacia.

O objetivo deste trabalho é discutir quais seriam as alternativas para tratamento dos efluentes no local e ao mesmo tempo, manter a dinâmica hídrica ali verificada, considerando o manejo da água em sua totalidade como forma de superar o atual modelo centralizado que, como apresentado, não resolve em absoluto o problema do tratamento dos efluentes.

\section{MATERIAL E MÉTODOS}

Para realizar os objetivos, buscou-se conhecer o projeto desenvolvido pelo SAEE para O Parque das Laranjeiras. Para tanto, foi necessário conhecer qual a situação das bacias hidrográficas presentes na cidade de Mogi Mirim. Em seguida, levantou-se informações sobre o assentamento em questão, descrevendo o histórico de ocupação e as dificuldades para a implantação da infraestrutura de saneamento no local. Por fim, foram considerados os 
motivos que levaram ao abandono de solução descentralizada de tratamento conforme recomendação da Política Nacional de Saneamento.

Para o presente estudo apoiou-se nos seguintes materiais disponibilizados pela equipe técnica daquele município: Plano Municipal de Saneamento Básico; Projeto executivo do sistema de coleta de esgotos e histórico da área (sistematizado por Magalhães, 2016). Além disso, foram analisados os seguintes documentos: Atlas de Esgoto (ANA, 2017); Plano Nacional de Saneamento (Brasil, 2013), além de artigos especializados na temática sobre sistemas descentralizados de esgotamento sanitário.

\section{DESENVOLVIMENTO}

\subsection{Situação do saneamento na cidade de Mogi Mirim}

Localizado a 50 km de Campinas, no estado de São Paulo, Mogi Mirim possui 92 mil habitantes, sendo que $85 \%$ desta vive em área urbana. Está inserido na Bacia Hidrográfica do Rio Mogi Guaçu e por sua vez, é dividido em outras três sub bacias: Mogi Mirim, Paraíso Cachoeira e Martin Francisco. (Figura 1).

Atualmente, a porcentagem de esgoto tratado que chega à ETE do município é de $65 \%$, no entanto, existem alguns bairros da sub bacia Mogi Mirim que não possuem redes de esgotamento, assim como toda a sub bacia Paraíso da Cachoeira, e a maioria do território da sub bacia Martin Francisco.

Figura 1 - Localização dos principais componentes do Sistema de Esgotamento Sanitário de Mogi Mirim.

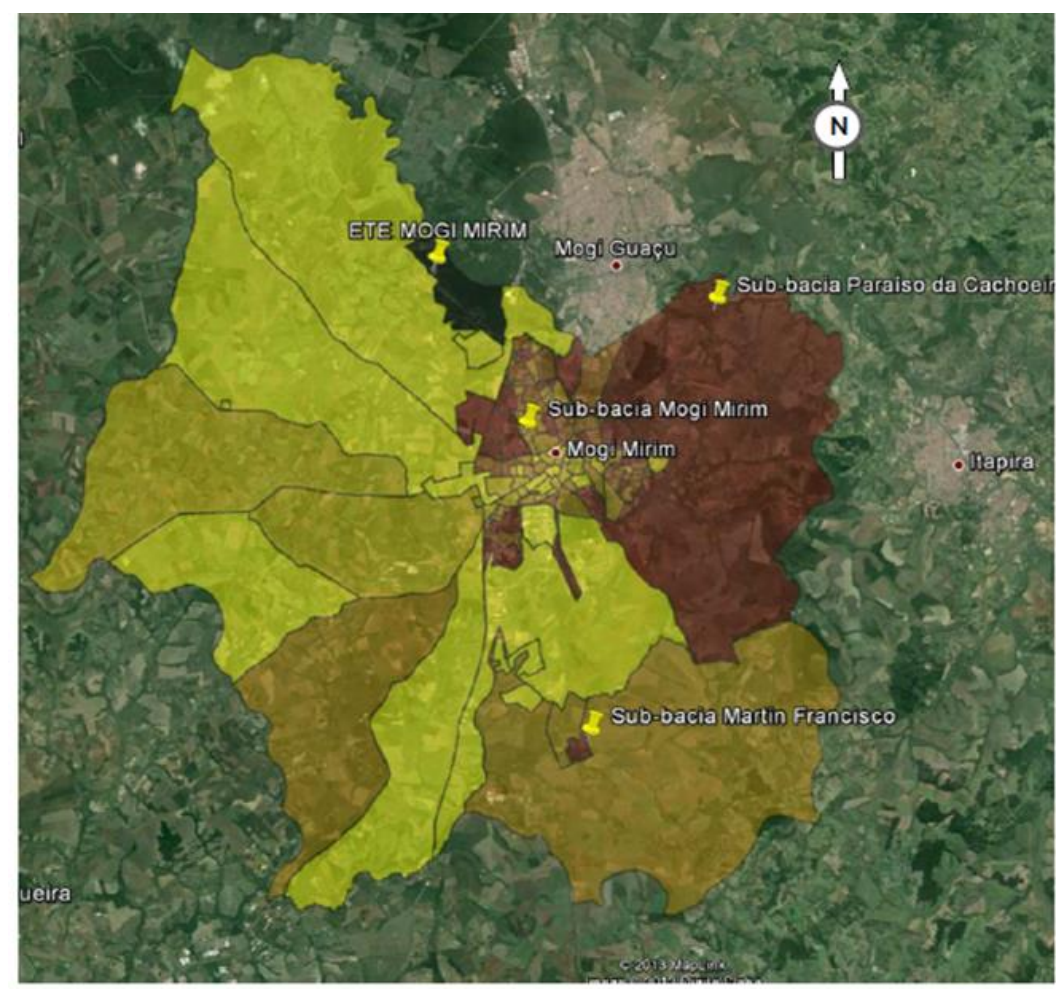

Fonte: Plano Municipal de Saneamento Básico de Mogi Mirim, SP

\subsection{O Parque das Laranjeiras}

Segundo Magalhães (2016), o loteamento fica no extremo leste da cidade, e se originou em 1982, quando a Empresa Loteadora de Terrenos (Emprelotes) aprovou o projeto de parcelamento do solo na Prefeitura. Entretanto, a empresa não registrou o loteamento em 
tempo hábil, e abandonou o empreendimento, deixando de lado a implantação de infraestrutura.

Conforme informações do Serviço Autônomo de Águas e Esgoto (SAAE) de Mogi Mirim, o projeto urbanístico original previa a implantação de 2521 lotes, sendo que parte do loteamento seria servido por fossas sépticas. Contudo, o SAAE recusou a proposta e exigiu a construção da rede de coleta para todo o bairro.

Em 1987 a Prefeitura conseguiu fazer a regularização de 519 lotes, em 200 mil metros quadrados, na área mais adensada do bairro. No entanto, a venda de lotes e ocupação irregular pelos compradores continuou de forma relativamente esparsa nos demais 800 mil metros quadrados. A partir de 2013 detectou-se também invasões em áreas de preservação permanente.

Localizada na sub bacia do Mogi Mirim, onde se encontra o Córrego do Boa. A Figura 2 apresenta as áreas de preservação permanente que guardam as nascentes do Córrego, bem como as vias sem pavimentação do bairro e os lotes sem ocupação.

Figura 2 - Parque das Laranjeiras e seu entorno.

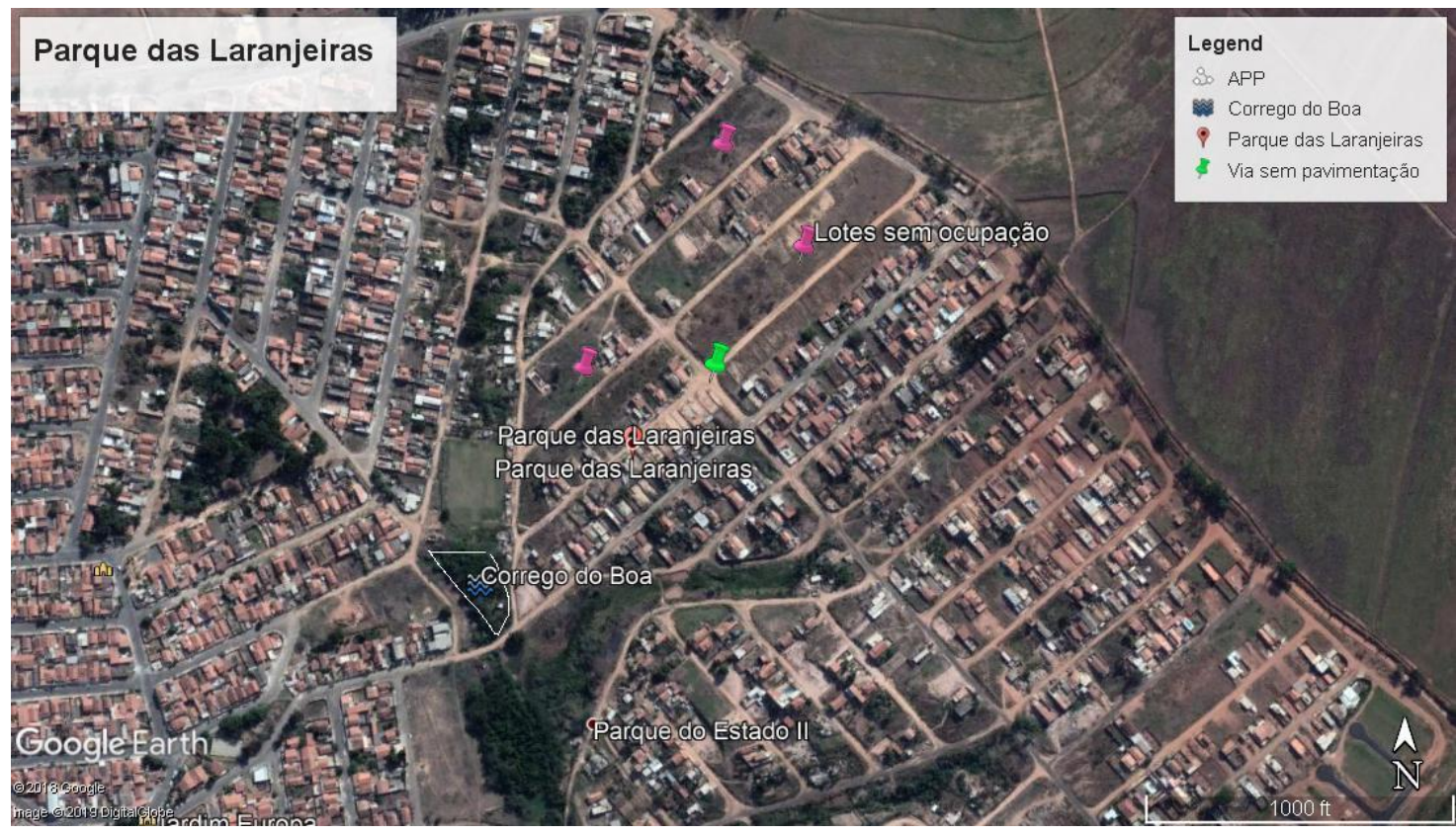

Fonte: Google Earth

A principal dificuldade para regularização do loteamento reside na ocupação de 11 áreas de preservação permanente dificultando as ações, já que a prefeitura estima a remoção de cerca de 190 famílias.

\subsection{A solução proposta pela Prefeitura e pelo SAAE}

Em 2018 a Prefeitura foi condenada judicialmente, em última instância, a regularizar todo o loteamento. Assim, foram elaborados os projetos executivos de infraestrutura, sendo que a solução para afastamento dos esgotos sanitários consiste na construção de uma estação elevatória que conduzirá os efluentes para a Estação de Tratamento de Esgotos - ETE de Mogi Mirim.

A adução deste efluente será feita da bacia do Córrego do Boa para a Bacia do Córrego do Toledo, sendo que nesta existe um coletor tronco que leva os efluentes da zona leste do município para a ETE. Esta solução, segundo o SAAE, é a única possível, já que para o esgotamento sanitário da bacia do Córrego do Boa, incluindo-se o Parque das Laranjeiras, é necessária a construção de um coletor tronco até o rio Mogi Mirim. Entretanto, essas obras não serão executadas em curto prazo pois fazem parte da última etapa do plano de investimentos do contrato de concessão do tratamento de esgotos. 
Por outro lado, a ETE ainda não está trabalhando em sua capacidade integral, e trata $65 \%$ dos esgotos de todo o município. O restante é ainda lançado in natura no Rio Mogi Guaçu, sob supervisão dos órgãos ambientais reguladores.

\subsection{O tratamento local de esgotos: discussão para o saneamento eficaz da bacia hidrográfica}

O fato dos esgotos do Parque das Laranjeiras serem conduzidos para a ETE, conforme a proposta do SAAE, tem alguns impactos que devem ser levados em conta. Neste trabalho destacamos os seguintes:

a) A transposição dos efluentes entre bacias hidrográficas: mesmo que se trate de esgotos domésticos, a transposição dos efluentes da bacia do córrego do Boa, onde é gerado, para a bacia do Córrego do Toledo, de onde seguirá em direção a ETE, conforme diretriz do SAAE, implica num movimento que adicionará à jusante, poluição hídrica. Esses efluentes poderiam ser devidamente tratados no local onde são gerados, com consumo reduzido de energia e lançamento no próprio corpo d'água, segundo a legislação vigente.

Uma solução que pode ser viável para assentamentos como o Parque das Laranjeiras são as ETE's compactas pois, são sistemas de fácil operação e manutenção e ocupam pouco espaço de implantação. Para que o lançamento ocorra no Córrego do Boa o órgão ambiental deve permitir o lançamento de efluentes que não exceda as condições e padrões de qualidade de água estabelecidos para a respectiva classe do corpo d'água. Segundo o Decreto Estadual n 10755/77 (SÃO PAULO, 1977) o Córrego do Boa é classificado como sendo de Classe 2.

Por outro lado, é necessário verificar também a vazão de efluentes gerada neste caso. Considerando o total de lotes no bairro, a população estimada para o local é de 8.824 pessoas. Considerando o volume de esgotos igual a $150 \mathrm{l} /$ pessoa/dia, de acordo com a NBR 7229 (ABNT,2013), isso geraria uma vazão de 15,3 l/s. Esta vazão adicional deve ser analisada mediante a capacidade natural do rio, no ponto de lançamento. O Decreto Estadual $n^{\circ}$ 8.468/1976 estabelece que o regime de lançamento deve exceder em no máximo 1,5 vezes a vazão média diária do manancial. Assim, o Córrego do Boa teria que ter no mínimo, a vazão de 10,2 l/s para atender a esta restrição.

Para regular a vazão de lançamento, uma opção para o tratamento é a utilização combinada da ETE compacta e um sistema natural, que permita o lançamento e ao mesmo tempo, amortecimento da velocidade.

b) Por estar no limite da zona urbana, e existirem atividades rurais muito próximas ao Parque das Laranjeiras e ao Córrego do Boa, cabe uma análise da possibilidade de reuso desses efluentes tratados na agricultura, por meio de adução para os sistemas de irrigação existentes. Esta solução poderia substituir o lançamento dos efluentes no Córrego do Boa, caso este não seja capaz de suportar as vazões resultantes do tratamento. Entretanto, o uso de resíduos em solos deve ser constantemente monitorado, para que não haja contaminação do sistema solo-água-planta. Para analisar a viabilidade deste projeto de reuso, é necessário verificar, nas redondezas, quais culturas agrícolas desenvolvidas, e também os sistemas de irrigação para que haja a devida substituição pelo sistema de adução do efluente.

\section{CONCLUSÕES}

Assentamentos urbanos como o Parque das Laranjeiras muitas vezes são negligenciados pelas autoridades locais, lembrados apenas em período eleitoral. A ausência de infraestrutura nessas áreas implica problemas ambientais e sociais, mas que podem ser superados com soluções mais econômicas do que as tradicionalmente praticadas.

A localização do assentamento nas bordas da cidade, junto à área rural, permitiria associar a instalação de uma ETE compacta, lançando no córrego do Boa o volume hídrico até o limite de sua capacidade, e o restante para irrigação ou infiltrado no solo. Inadmissível é persistir no modelo centralizado que transpõe os efluentes para outra bacia, onde efetivamente não será tratado. Este caso ilustra uma situação recorrente em muitos 
municípios brasileiros, mesmo após investimentos em saneamento, ainda enfrentam problemas da polvição de corpos d'água por esgotos não tratados.

\section{AGRADECIMENTOS}

Agradeço à CAPES pela concessão da bolsa de mestrado, que viabilizou esta pesquisa.

\section{REFERÊNCIAS}

ANA. Agência Nacional de Águas. Atlas Esgotos: Despolvição de Bacias Hidrográficas (2017). Disponível em: http://atlasesgotos.ana.gov.br/ Acesso em: mar. 2019.

ABNT. ASSOCIAÇÃO BRASILEIRA DE NORMAS TÉCNICAS. NBR 7229: Projeto, construção e operação de sistemas de tanques sépticos. Rio de Janeiro: ABNT "Associação Brasileira de Normas Técnicas", 2003.

BRASIL. CONAMA 357/05. "Dispõe sobre a classificação dos corpos de água e diretrizes ambientais para o seu enquadramento, bem como estabelece as condições e padrões de lançamento de efluentes, e dá outras providências", Brasília, 17 mar. 2005. Disponível em: <http://www2.mma.gov.br/port/conama/legiabre.cfm?codlegi=459>. Acesso em: abr. 2019.

BRASIL. CONAMA 430/2011. Dispõe sobre as condições e padrões de lançamento de efluentes, complementa e altera a Resolução no 357, de 17 de março de 2005, do Conselho Nacional do Meio Ambiente-CONAMA. Brasília, 16 mai. 2011. Disponível em:

<http://www.mma.gov.br/port/conama/legiabre.cfm? codlegi=646>. Acesso em: abril 2019.

BRASIL. Léo Heller. Secretaria Nacional de Saneamento Ambiental (Org.). Plano Nacional de Saneamento Básico - PLANSAB. Brasília, 2013. Disponível em:

<http://www.mma.gov.br/port/conama/processos/AECBF8E2/Plansab_Versao_Conselhos_N acionais_020520131.pdf>. Acesso em: março 2019.

LIBRALATO, Giovanni; GHIRARDINI, Annamaria Volpi; AVEZZÙ, Francesco. To centralize or to decentralize: An overview of the most recent trends in wastewater treatment management. Journal of Environmental Management, fev. 2012.

MAGALHÃES, Flavio José Araújo de; Eterna Promessa: os caminhos tortuosos dos moradores do Parque das Laranjeiras. A Comarca, São Paulo/SP, 2016. Edição Especial.

SANTOS, D. G. Visão da ANA sobre o reuso de agua advinda de esgotos para fins agrícolas e florestais. Agência Nacional das Aguas, 2016. Disponível em:

http://www.aidisnet.org/PDF/16etan/Reuso\%20de\%20Aguas\%20-\%20Devanir_ANA.pdf

Acesso em 21 abr. 2019.

SÃO PAULO (Estado). Decreto Estadual no 8468, de 8 de setembro de 1976. Aprova o Regulamento da Lei $\mathrm{n}^{\circ}$ 997, de 31 de maio de 1976, que dispõe sobre a prevenção e o controle da polvição do Meio Ambiente. Diário Oficial do Estado, São Paulo, 01 jun. 1976. Disponivel em:<https://www.cetesb.sp.gov.br/Institucional/documentos/Dec8468.pdf> Acesso em: mar. 2019.

SÃO PAULO (Estado). Decreto n 10.755, de 22 de novembro de 1977. Dispõe sobre o enquadramento dos corpos de agua receptores na classificação prevista no Decreto $\mathrm{n}^{\circ}$ 8468, de 8 de novembro de 1976, e dá providências correlatas. Diário Oficial do Estado de São Paulo, Diário do Executivo, São Paulo, v.87, n. 221, 23 de nov. 1977. Disponível em: http://www.CETESB.sp.gov.br/licenciamentoo/legislacao/estadual/decretos/1977_Dec_Est_1 075.pdf. Acesso em: abr. 2019. 
SERVIÇO AUTÔNOMO DE ÁGUA E ESGOTO DE MOGI MIRIM. Plano Municipal de Saneamento Básico de Mogi Mirim 2014 - 2034. Mogi Mirim, jan. 2014. Disponível em

http://saaemogimirim.sp.gov.br/files/PMSBMogiMirimCOMPLETOR1.pdf. Acesso em 22 abr 2019. 